\title{
Paisajes y relatos de vida. Apuntes para la interpretación de los paisajes socioculturales con mención a Puntarenas y Limón (centro) en Costa Rica*
}

\author{
Allen Cordero Ulate** \\ Escuela de Sociología \\ Universidad de Costa Rica
}

\section{Resumen}

El presente artículo busca combinar conceptos de distintas ciencias sociales para plantear una definición de paisaje. Propone que la historia del paisaje es también una historia social y, por lo tanto, se expresa en historias individuales sobre la construcción y la vivencia del paisaje, de ahí que postule una metodología de relatos de vida para estudiarlo. Se pretende fundamentar teóricamente la recopilación de relatos de paisajes en Puntarenas y Limón, destinos históricos del turismo (donde se originó el turismo en Costa Rica) en este país.

\section{Palabras clave}

Paisaje socio-cultural, relatos de vida, Costa Rica

\footnotetext{
* Este texto se ha elaborado en el marco del proyecto Centros Históricos del Turismo: Puntarenas y Limón, de la Escuela de Sociología y las sedes de El Pacífico y de Limón de la Universidad de Costa Rica. Agradezco a mis colegas del equipo de investigación: profesoras(es) Susan Chen, Jorge Bartels, Pablo Carballo, Ivonne Lepe, Bladimir Argueta, Cynthia Arrieta y Diana Guardia, quienes han comentado y recreado las ideas aquí planteadas.
}

Recibido: 17/02/2014 · Aceptado: 06/03/2014

**Correo electrónico: allen.cordero@ucr.ac.cr 


\title{
Landscapes and life histories: notes for the interpretation of socio-cultural landscapes in Puntarenas and Limón, Costa Rica.
}

\author{
Allen Cordero Ulate** \\ Escuela de Sociología \\ Universidad de Costa Rica
}

\begin{abstract}
This paper is an attempt to combine concepts of different social sciences to propose a landscape definition. The history of landscape is a social history as well and therefore finds expression in personal histories about the construction and experience of the landscape; a research methodology based on these Life Histories is proposed. It seeks to theoretically sustain the collection of landscape histories in Puntarenas and Limón, Costa Rica's historical tourism destinations.
\end{abstract}

KEY WORDS

Socio-cultural landscape, life histories, Costa Rica

**E-mail: allen.cordero@ucr.ac.cr 


\section{Definición general del paisaje}

El paisaje es un dato de la geografía; es la forma como se organiza la materia en un espacio dado. En su conformación concurre un conjunto de elementos siempre en movimiento: la propia materia, el modo de producción que se asienta sobre el espacio geográfico a través de la historia cambiante, factores de la acción social como las luchas sociales tendientes a modificar o transformar los modos de producción y sus consecuencias socioculturales. El paisaje es vivido por los grupos sociales y por los individuos, quienes lo reconstruyen de manera permanente y lo perciben no solo en el trabajo, sino también en la vida cotidiana. Asimismo, es una experiencia subjetiva, vivida en una constante dialéctica entre la enajenación y la liberación y, para los individuos, el paisaje es, al mismo tiempo, objetivo y subjetivo. Objetivo porque el trabajo y la lucha social son categorías objetivas, y subjetivo porque se le experimenta de un modo subjetivo. En este sentido, por ejemplo, en circunstancias y espacios particulares, la explotación puede ser percibida como "placentera", es el caso de un trabajador que compara su situación con la de un desempleado.

\section{Juego entre materia y modos de producción}

El primer dato del paisaje, su determinación fundamental, es material, en cierta medida geológica y geográfica. Geológica porque se relaciona con los cambios materiales de la tierra; su proceso de transformación desde la prehistoria hasta el presente, los movimientos profundos de la materia que han dado lugar a la aparición de masas de tierra separadas de los mares y océanos, así como a las islas. Paisaje es, igualmente, la composición de la atmósfera terrestre y hasta la visión del aire y del cielo, ${ }^{1}$ la conformación concreta de los ríos, valles y montañas, con sus alturas específicas respecto del nivel del mar y, más arriba, las calidades atmosféricas; la lucha permanente entre tierra, agua y aire, entre otros elementos. ${ }^{2}$

${ }^{1}$ Decimos visión del aire y del cielo pues de acuerdo con la composición del aire este puede ser visto de distintas maneras. Por ejemplo, un aire muy contaminado con humo industrial, el llamado esmog, puede nublar la visión del cielo.

${ }^{2}$ Como se verá más adelante, la materia determina incluso a los paisajes urbanos. 
Paisajes y relatos de vida. Apuntes para la interpretación de los paisajes socioculturales.

Como ya lo había dicho Jean Paul Sartre, memorable filósofo, la materia representa la condición de la historicidad. Es el motor pasivo de la historia:

La materia, en tanto que pura materia inhumana e inorgánica (lo que quiere decir no en sí sino en el estadio de la praxis en que se descubre la experimentación científica) está regida por leyes de exterioridad. Si es verdad que realiza una primera unión de los hombres, debe ser en tanto que el hombre prácticamente ha intentado ya unirle y que ella soporta pasivamente el sello de esta unidad [Sartre, 1960: 200]. ${ }^{3}$

Con la aparición paulatina de la humanidad que, como se sabe, fue fruto de un largo proceso histórico, se establecen formas de relacionamiento con la materia 0 , en otras palabras, con la naturaleza externa a la humanidad: los modos de producción. Es decir, las formas en que la sociedad se organiza para extraer de la naturaleza lo que necesita para vivir; por supuesto, el mundo de la economía. ${ }^{4}$

Cuando el modo de producción es demasiado primitivo o elemental, los impactos sobre la materia casi son imperceptibles; predomina, por tanto, el paisaje puramente natural. En la medida en que la historia ha sido la de la transformación de los sistemas productivos o modos de producción y, por consecuencia, estos se han vuelto más complejos, se ha colocado, más allá de la sobrevivencia material inmediata de la humanidad, el tema central de la producción y la acumulación del excedente. Hasta llegar a la historia contemporánea, donde el modo de producción se enfrenta en una lucha casi mortal y suicida de transformación de la naturaleza, en busca de acumulaciones de excedentes nunca antes vistas. En este contexto, el paisaje es alterado y modificado en gran parte por la humanidad, organizada bajo un modo de producción capitalista dominante en todo el mundo.

En el modo de producción actual, el capitalista, la evolución económica se concreta en una organización específica de determinados ejes de acumulación,

${ }^{3}$ En la versión original: "La matière est, en tant que pure matière inhumaine et inorganique (ce qui veut dire non pas en soi mais au stade de la praxis ou elle se découvre à l'expérimentation scientifique), régie par des lois d'extériorité. S'il est vrai qu'elle réalise une première unión des hommes, ce doit être en tant que l'homme a déjà tenté pratiquement de l'unir et qu'elle supporte passivement le sceau de cette unité".

${ }^{4}$ La categoría modo de producción constituye uno de los grandes conceptos articuladores del pensamiento marxista. La bibliografía es muy abundante, pero para hacer referencia a algunos textos clásicos pueden mencionarse: Contribution à la critique de l'économie politique (Marx, 1972); Le capital Critique de l'economie politique (Marx, 1948). Un extraordinario estudio sobre la historia de los modos de producción hasta el capitalismo de los años sesenta sigue siendo el Traité d'économie marxiste (Mandel, 1974). 
es decir, las actividades económicas centrales mediante las cuales se extrae el excedente económico. Así, los ejes de acumulación son una categoría intermedia entre modo de producción y paisaje, que organizan de manera concreta la economía, lo que implica al mismo tiempo impactos paisajísticos.

Un texto clásico del paisaje, Antropología del paisaje. Climas, culturas y religiones, de Tetsuro Watsuji (2006; publicado en 1937 como primer capítulo de su Ética), defiende una perspectiva determinista del paisaje en el desarrollo cultural y, específicamente, de la persona humana. Desde la filosofía existencialista de corte heideggeriana de la que parte Watsuji, nos encontramos con nosotros mismos en correlación existencial con el clima y el paisaje (Watsuji, 2006: 28). Así que, ampliando la centralidad existencial que Heidegger le otorgó al tiempo, Watsuji le agregará al ser la categoría articuladora del espacio. Según este autor, el ser humano no solo es temporalidad sino también espacialidad: "clima y paisaje constituyen el momento de objetivación de la subjetividad humana en el que el ser humano se comprende a sí mismo" (Watsuji, 2006: 38). Los perfiles psicosociales elaborados por el filósofo japonés son contundentes sobre la preeminencia paisajística. Las personas presentan características diferentes en correspondencia con el ambiente. Tres serán los grandes perfiles trazados por él de acuerdo con su contexto paisajístico; el monzón, correspondiente a la zona costera de Asia oriental, China y Japón, donde la combinación de humedad con calor da lugar a una agricultura prodigiosa sobre la que ha emergido una cultura signada por el agradecimiento a la naturaleza y una visión de la vida -teoría de la transmigración, de la India- que unifica distintas especies, por ejemplo, los animales y el hombre. El segundo es el desierto, el clima de Arabia, África y Mongolia; se trata de la desnudez excesiva de las afiladas piedras, donde se presenta el extremo contrario, la naturaleza inclemente y, por tanto, la lucha por los escasos pozos, lo que origina que diferentes grupos luchen ferozmente entre sí. Los dioses erigidos sobre este paisaje son los de las grandes religiones que perviven hasta el presente, dioses abstractos, despegados de la naturaleza, dioses filosóficos, que buscan unificar lo existente mediante conceptos totalizantes (Watsuji, 2006: 66-86). Por último, está la dehesa, el paisaje europeo, la "llanura de hierba verde". Al respecto, Watsuji explica que el maquinismo y la fábrica no son más que una derivación de esa pradera abundante (2006: 89).

Todo lo contrario de esta posición ha sido expresado por Alain Roger (2007), para quien el paisaje es una creación de la cultura y fundamentalmente del arte. 
Paisajes y relatos de vida. Apuntes para la interpretación de los paisajes socioculturales.

Así, la naturaleza no se imita, sino que se recrea, ni tampoco es una especie de madre fértil, sino que el ser humano le da vida mediante su inteligencia y las creaciones culturales. Por ejemplo, el arte inventó la neblina; nadie le ponía atención hasta que el arte la descubrió. Al proceso de inventar artísticamente a la naturaleza, a partir de una palabra procedente de Montaigne, se le denomina "artealizar la naturaleza" (Roger Alain, 2007: 21). Hay dos maneras de artealizarla. La primera es in situ, es decir, por medio de actuaciones directas sobre el espacio natural. Y, la segunda, in visu, mediante la mirada. En el cuerpo femenino, por ejemplo, el in situ es actuar sobre él a través de maquillajes, tatuajes o escarificaciones. ${ }^{5}$ La forma in visu funciona recurriendo a modelos, es el caso del desnudo, que implica la mirada del artista y el entendimiento de esta mirada por parte del espectador, lo que ordinariamente conlleva recreaciones o reinterpretaciones de la mirada artística. En este sentido, la mirada del artista y la del espectador se hablan y se ratifican entre sí. "La naturaleza es indeterminada y solo el arte la determina: un país no se convierte en paisaje mas que bajo la condición de un paisaje, y esto de acuerdo con las dos modalidades, móvil (in visu) y adherente (in situ), de la artealización” (Roger, 2007: 23). ${ }^{6}$

Los sitios del paisaje se "realizan" porque habitan nuestra mirada, y la habitan por intermedio de la cultura, sobre todo del arte. En cuanto a los paisajes rurales o silvestres, muy consecuente con su postura culturalista-artística, Roger sostiene que los campesinos no tienen paisaje, pues para ellos el entorno es "natural", algo así como un lugar para trabajar. El autor recuerda que, para Kant, el paisaje sublime se presenta al hombre rudo "simplemente como pavoroso" (Roger, 2007: 31). ${ }^{\text {? }}$

Es decir, quien ignora la mirada artística no forzosamente la compartirá. Pero, desde nuestra perspectiva y manteniéndonos en un espacio de crítica

${ }^{5}$ Escarificaciones: incisiones superficiales en la piel humana.

${ }^{6}$ En la edición francesa: "La nature est indéterminée et ne reçoit ses déterminations que l'art: du pays ne devient un paysage que sous la condition d'un paysage, et cela, selon les deux modalités, mobile (in visu) et adhérente (in situ), de l' artialisation" (Roger, 1997: 17-18).

${ }^{7}$ La centralidad que da Roger a la mirada me hace recordar el tema de la imagen y de lo imaginario en Jean Paul Sartre, para quien la imagen es un estado de conciencia, un objeto mental o "un irreal" cuyo contacto con la realidad no necesariamente es estrecho. La imagen funciona como un analogon, de la realidad, pero no por fuerza como su reproducción (mucho menos fiel de la misma). En el caso del arte, para Sartre: "Desde el cubismo se tiene la costumbre de declarar que el cuadro no tiene que representar o imitar, sino que tiene que constituir un objeto por sí mismo" (Sartre, 1964: 235). Esta idea podría asimilarse a la pintura de paisajes, que no busca imitar puntillosamente el paisaje pintado, sino que es, por así decirlo, una idea artística, cuyo trasfondo está dado por un espacio real, pero secundario para la idea. 
puramente cultural, podríamos decir que quizá los campesinos o los habitantes de un paisaje sujeto a la mirada artística especializada no carecen de miradas paisajísticas y, por ende, culturales, sino que tal vez ignoran ciertas maneras de observar los propios espacios en que habitan y trabajan. A lo mejor las estéticas paisajísticas campesinas se encuentran en efecto ancladas de una forma más directa a la utilidad productiva del paisaje, pero eso no quiere decir que no sean válidas en tanto miradas, y no se puede descartar que estas estéticas campesinas estén en posibilidad de ser recreadas por el artista; es decir, un movimiento cultural relativamente inverso, en donde la mirada del habitante local es retomada por el artista y no al revés, donde el artista supremo impone su mirada ignorando las miradas campesinas.

Desde la posición interdisciplinaria, vale destacar el libro La construcción social del paisaje, editado por Joan Nogué (2007), que recoge las contribuciones del Seminario Internacional sobre Paisaje, realizado en el otoño de 2004 y 2005. Para el editor, "el paisaje puede interpretarse como el resultado de una transformación colectiva de la naturaleza y como la proyección cultural de una sociedad en un espacio determinado" (Nogué, 2007: 11-12). En la construcción social de este paisaje intervienen diversos elementos de la realidad social, entre estos, "maneras de ver", en cierto grado coincidentes con la postura de Roger: las formaciones sociales urbanas, que a pesar de sus polos de "desarrollo" y "subdesarrollo" contradictorios y dispares se encuentran interconectadas; la ideología que sirve como filtro del gusto. El concepto de paisaje del autor hace recaer el peso interpretativo en la cultura, pues: "el paisaje es un concepto fuertemente impregnado de connotaciones culturales y puede ser interpretado como un dinámico código de símbolos que nos habla de la cultura de su pasado, de su presente y tal vez también de la de su futuro" (Nogué, 2007: 21).

Esta última apreciación coincide hasta cierto punto con la definición de paisajes culturales de la Organización de las Naciones Unidas para la Educación, la Ciencia y la Cultura (Unesco), a saber, aquella que los conceptualiza como las obras que combinan el trabajo del hombre y la naturaleza. El concepto paisaje cultural incluye, para esa organización, una diversidad de manifestaciones de la interacción entre el hombre y su ambiente natural. Al respecto, la Unesco ha elaborado una tipología que incluye:

- Aquellos paisajes culturales claramente definidos, diseñados y creados de manera intencional por el hombre, como los jardines y los parques. 
Paisajes y relatos de vida. Apuntes para la interpretación de los paisajes socioculturales.

- Los paisajes evolutivos (u orgánicamente desarrollados) resultantes de condicionantes sociales, económicos, administrativos y religiosos que se han desarrollado en conjunto y en respuesta a su medio ambiente natural (Unesco, 2002: 10).

Esta última categoría de paisajes concuerda con más precisión con nuestra propuesta de entender el paisaje como el resultado físico de la combinación entre naturaleza y modo de producción.

Desde nuestro punto de vista, los paisajes son construidos (y destruidos) continuamente por la humanidad, y la economía es su principal factor de (re) configuración. En términos de acción humana, la categoría trabajo sería el principal determinante social de la (re)creación de los paisajes. El trabajo es, entonces, el gran modificador del paisaje, pues, en tanto actividad humana, concreta el modo de producción, con su combinación específica de ejes de acumulación.

Vale indicar que el trabajo es la principal fuerza productiva. Hasta el momento, incluso la técnica es dependiente del trabajo, en razón de que aun la tecnología es un producto del trabajo, ya que para producirla y operarla se requiere trabajo (calificado y "no calificado"). Claro está que el trabajo se potencia con la técnica, produciendo grandes impactos productivos, pero también paisajísticos.

La investigación de Don Mitchell, "Muerte entre la abundancia: los paisajes como sistemas de reproducción social” (2007), es muy ilustrativa sobre los impactos paisajísticos urbanos derivados de las relaciones sociales marcadas por la explotación del trabajo. El ejemplo a partir del cual estructura su reflexión no puede ser más expresivo: el cementerio municipal de Holtville, ubicado en el Valle Imperial, desértica planicie al este de San Diego, California, donde bajo pequeñas lápidas anónimas son enterrados los indocumentados migrantes procedentes de México y Centroamérica que no logran llegar al destino que se habían propuesto, ni emplearse en las ultramodernas plantaciones agrícolas californianas o en las ocupaciones usuales en que se insertan los latinos sin papeles de residencia en Estados Unidos. Fallando en tal propósito, terminan en este inmenso cementerio anónimo que recibe más de 300 cuerpos al año. Es esta la otra cara de la moneda de la prosperidad estadounidense. Pero tan legítimo es este paisaje como el de su contraparte urbana elegante y suntuosa. Así: "El cementerio de pobres no está solo en el paisaje” (Mitchell, 2007: 105). 
La mayoría de los paisajes urbanos están determinados por las obras de infraestructura, tales como carreteras, distribución urbanística, obras públicas, almacenes, puertos, aeropuertos, etc., que se asientan en una geografía dada y juegan con ella. Los criterios estéticos de urbanistas, técnicos e ingenieros se combinan con los criterios políticos y las luchas sociales originando paisajes físicos, pero que son mediados social y políticamente. Esto se corresponde en parte con la dialéctica entre las categorías espaciales de poder planteadas por Lefebvre y que son:

a) las prácticas espaciales, formas mediante las que generamos, utilizamos y percibimos el espacio;

b) representaciones del espacio, aquellas realizadas por oficinas técnico-científicas, urbanistas, tecnócratas que, por ejemplo, producen mapas que van a ser instrumentados por instituciones estatales dominantes, como institutos geográficos, etc. y, por último,

c) espacios de representación, aquellos espacios donde se expresan las distintas contradicciones por la representación del espacio; es decir, el espacio imaginado por los sectores sociales subalternos que son los que hacen uso del espacio.

Estas representaciones pueden estar en contradicción con la producción de mapas indicada en la categoría anterior (Oslender, 2002). Esta categorización de Lefebvre, retomada por Oslender para analizar la formación identitaria de los movimientos sociales de base territorial, se sitúa en el terreno de lo social y de lo político, siendo la categoría de prácticas espaciales el concepto más directamente materialista, pues se refiere al uso práctico del espacio, mientras que las otras dos categorías -representaciones del espacio y espacios de representación- pueden entenderse como luchas de poder simbólico, es decir, mapas oficiales y jerárquicos que manifiestan a los sectores dominantes (representaciones del espacio) en contraposición a los imaginarios sociales del espacio de que son portadoras las clases sociales subalternas, que se desempeñan de manera práctica en espacios dados (espacios de representación).

El elemento adicional que estamos recordando en nuestra conceptualización del paisaje es el directamente material, es decir, la determinación de la materia misma, de la tierra con sus accidentes específicos. Hasta en los paisajes más historizados, aquellos donde la historia del comercio y de la acumulación de 
Paisajes y relatos de vida. Apuntes para la interpretación de los paisajes socioculturales.

excedentes tiene más de tres mil años, pueden seguirse observando fundamentales determinaciones puramente geográficas. Piénsese, por ejemplo, en una ciudad como Estambul, con una historia milenaria, pero donde las tres categorías mencionadas han debido estructurarse sobre una geografía que no ha podido ser borrada: el extraordinario juego entre mares (el Negro y el de Mármara), el estrecho de Bósforo, una angosta bahía (el Cuerno de Oro) y una geografía terrestre accidentada y quebrada con colinas y ondulaciones.

Por lo tanto, es posible postular que hay una autonomía relativa del paisaje respecto del modo de producción y su historia. $\mathrm{O}$ bien puede formularse su contrario: hay una autonomía relativa del modo de producción respecto del paisaje. En el contexto del capitalismo triunfante del siglo xix, parecía que el modo de producción dominaba sobre el paisaje. Pero con el cambio climático, del que se es más consciente en la actualidad, cabe la duda de si el clima y, por consiguiente, la naturaleza dominan y determinan a la sociedad y, en consecuencia, al modo de producción.

En el ámbito de lo social, el trabajo es la práctica espacial por excelencia; la actividad humana que altera y reconstruye el paisaje, tanto urbano como rural. La relación entre trabajo y paisaje es evidente en una actividad económica del tipo de la construcción, por supuesto muy vinculada con el desarrollo urbano, pero asimismo con algunas obras de impacto rural como las carreteras o las represas hidroeléctricas. Sin embargo, cualquier trabajo humano que materializa el modo de producción reconstruye el paisaje, no solo la construcción. Ya que el uso del espacio recrea el objeto de que se trate, hasta cierto punto lo legitima espacialmente 0 , desde nuestra perspectiva, al usar los objetos que constituyen parte del paisaje, estos se legitiman y así se reconstruye el paisaje. El impacto paisajístico de la construcción de una línea ferroviaria es tremendo; los trabajadores de las obras de construcción pueden sentir cómo, mediante su trabajo diario, el paisaje va cambiando de forma radical. Puede postularse una conciencia inmediata de la reconstrucción del paisaje por parte de estos trabajadores. Pero el pasajero de ese tren también reconstruye el paisaje porque legítima la vía férrea mediante su uso, y con ello legitima una modificación paisajística. Pero es más difícil, quizá, que un pasajero de tren tenga conciencia de que está alterando el paisaje, tal vez se puede autopercibir, a lo sumo, como un contemplador del nuevo paisaje. 


\section{Luchas sociales y paisajes}

Las clases y grupos sociales que se estructuran en el modo de producción modelan socialmente el paisaje. Por una parte, los grupos dominantes darán forma a sus proyectos económicos, bajo la modalidad de "planes de desarrollo", que serán sus propuestas de políticas para agenciar sus intereses económicos. En otras palabras, los nuevos ejes de acumulación se materializarán mediante políticas de desarrollo y la actividad económica como tal. En el marco del capitalismo, el "desarrollo" es entendido como una división del trabajo entre mercado y Estado.

En el contexto del desarrollismo latinoamericano, el Estado era visto de una manera más protagónica tanto en lo social como en lo económico, mientras que en el neoliberalismo se han reducido las funciones del Estado. Cada combinación de política específica entre Estado y mercado ha tenido sus correspondientes impactos paisajísticos. Puntarenas y Limón (centro), los paisajes urbanos que son objeto de esta reflexión, fueron muy determinados por su función de puertos de exportación, por ser los pilares de la circulación de mercancías hacia el exterior y, por lo tanto, de vinculación con el mercado internacional; máxima expresión del mercado en Costa Rica. La inversión, pública y privada, se dirigió a la construcción de los puertos y los ferrocarriles. El paisaje predominante de estos lugares se estructuró en torno a estas obras de infraestructura.

A su vez, las clases o grupos sociales que se encuentran en posiciones de desventaja en este modo de producción no son determinados fatalmente por la exclusión, sino que además han echado mano de recursos de lucha social o movimientos sociales para defenderse y resistir a ubicaciones espaciales concretas derivadas de las desigualdades sociales. De forma tal que, históricamente, se ha asistido a luchas sociales redistributivas del excedente (aquellas disputas en torno al valor de la fuerza de trabajo relacionadas con la redistribución del excedente generado). Incluso estas luchas tienen impactos paisajísticos, pues dependiendo del valor de la fuerza de trabajo se puede o no acceder a ciertas viviendas y vecindarios, así como a una calidad de transportes y servicios públicos específica.

Las luchas sociales urbanas, entre estas las vinculadas con vivienda, transportes, defensa o creación de espacios públicos, o bien a la demanda de servicios públicos como agua, electricidad, educación o salud, son otro tipo de 
Paisajes y relatos de vida. Apuntes para la interpretación de los paisajes socioculturales.

luchas de fuertes consecuencias en el nivel y la calidad de vida de grandes conglomerados sociales. Aquí también puede hacerse una lectura paisajística de tales movimientos sociales, en razón de que estas obras dan lugar, en parte, a la conformación del paisaje urbano.

Cuando los movimientos sociales no se quedan solo en la demanda de tal o cual servicio, sino que opinan sobre las características que deben conllevar algunas obras, puede decirse que son portadores de estéticas urbanísticas; lo que en algunas circunstancias puede implicar juicios y criterios paisajísticos. ${ }^{8}$ Esto ocurre cuando, por razones estéticas e históricas, se rescatan edificios, parques u obras antiguas. Hay una lucha urbana típicamente paisajística en aquella asociada con la altura y la ubicación de los edificios, debido a que sectores de la población pueden verse afectados por obras de infraestructura, mientras que otros podrán ser directamente beneficiados.

Tal como lo postuló Castells en un clásico de los movimientos sociales urbanos ya casi olvidado, los grandes modificadores de la ciudad son los movimientos sociales urbanos y no necesariamente las instituciones de planificación urbana. Estos movimientos serían resultado de los cambios en el consumo colectivo y de las nuevas contradicciones sociales que genera la expansión capitalista en la ciudad (Castells, 1974: 10).

El paisaje rural es de igual forma influido por la expansión del capital, por una parte, y por las luchas de los grupos sociales en sus diversas modalidades, por otra. Este paisaje es marcado y remarcado por los productos que concretan los nuevos ejes de acumulación en el nivel rural, ya sean productos dirigidos al mercado nacional o al internacional, o bien cuando se trata de un eje de consumo internacional pero que se realiza en el terreno local, como sucede con el turismo. Del mismo modo, las obras de infraestructura y la organización de los servicios se pondrán a disposición de los actores que concretan los nuevos ejes de acumulación. Pero, así como sucede con los actores urbanos excluidos, en el ámbito rural los excluidos pueden echar mano de herramientas de movimientos sociales, entre otras las que se expresan en la disputa de los excedentes del valor de la fuerza de trabajo o las relativas a la vivienda y los servicios. Unos y otros movimientos modifican y determinan finalmente el paisaje rural.

${ }^{8}$ Naturalmente, los movimientos sociales interactúan con diversos actores sociales, por ejemplo desarrolladores urbanos, partidos políticos locales o nacionales, organizaciones no gubernamentales, funcionarios públicos de oficinas especialistas en el ordenamiento territorial, entre otros, que consciente o inconscientemente también serán portadores de estéticas urbanas. 
Por ejemplo, en amplias extensiones de su territorio, el paisaje rural limonense fue marcado por las plantaciones bananeras articuladas en torno a los ferrocarriles, que eran, por así decirlo, como las venas en el sistema circulatorio del cuerpo humano, que hacen circular la sangre por todo el cuerpo. En este caso, el banano, cual sangre económica, circulaba a través de las venas del abigarrado sistema ferroviario penetrando las plantaciones y llevando los bananos hacia las arterias principales y de ahí hasta el puerto. El gran periodo del sindicalismo costarricense fue el del sindicalismo bananero, y a sus luchas se debe buena parte de las llamadas conquistas sociales de que hace gala Costa Rica. Todavía en la actualidad gran parte del paisaje caribeño es bananero, pero el tren, ahora abandonado, ha dejado paso a los contenedores (containers), que son apilados en vastos espacios y luego depositados en inmensos barcos mediante sistemas modernos de montacargas y grúas. El paisaje ha cambiado mucho, pero la savia económica bananera que circula por las venas de la economía caribeña sigue siendo ante todo la seña distintiva de estos paisajes que articulan la ruralidad y el espacio urbano de la región. El tren fue escenario sindicalista; el contenedor, por el contrario, de la desorganización posterior a la feroz persecución antisindical en las fincas bananeras. El contenedor es una expresión paisajística de la eficiente organización de los transportes bananeros en la actualidad; paisaje aséptico y despersonalizado.

\section{Vida cotidiana y paisaje}

Entendemos vida cotidiana como la practicada principalmente en el orden individual y/o familiar y cuyo lugar de realización es el ámbito privado de las viviendas. Además, puede agregarse a esta definición la vida en los barrios, ciudades o pequeños pueblos rurales o semirrurales, pero que no es una acción colectiva consciente, sino acciones rutinarias como compras, uso de servicios variados, peluquerías, tiendas de abarrotes, servicios de salud y diversión, entre otros. En cierto modo, vida cotidiana engloba la mayor parte de la vida, pues los "grandes" hechos de la historia no ocurren todos los días, sino que son hitos de ruptura con la cotidianidad o la continuidad de las rutinas sociales. Desde este punto de vista, la vida cotidiana no se independiza por completo de la historia, sino que constituye la historia fragmentada e individualizada, tal como lo planteó Agnes Heller (1972). Existe una dialéctica entre vida cotidiana 
Paisajes y relatos de vida. Apuntes para la interpretación de los paisajes socioculturales.

rutinaria y fragmentada, por un lado, y vida cotidiana consciente y ligada a la acción colectiva por el otro. Esta última forma de vida cotidiana es la que con más frecuencia se asocia a los grandes acontecimientos históricos.

Pero póngase el énfasis, al menos por un momento, en la vida cotidiana individualizada y fragmentada. Aquella que tiene por escenarios preferidos la vivienda y el barrio, incluso si este es un barrio inmerso en grandes ciudades. Este ámbito es el de las decisiones aparentemente íntimas e independientes de determinaciones sociales, libres de determinaciones provenientes del modo de producción o de la geografía. ${ }^{9}$

Mas basta una mirada, incluso superficial, de esta vida cotidiana para darse cuenta de que es un ámbito notable de producción paisajística. Algunos de los aspectos donde impacta son la propia vivienda y los usos y reconstrucciones de los barrios. La vivienda, su elección y sus criterios estéticos tienen tremendos efectos paisajísticos, pues se relacionan, entre otras cosas, con los materiales, los colores, la altura, los adornos externos e internos, los jardines, etc. Igual ocurre en los barrios donde sucede la vida diaria, pues constituyen espacios en permanente legitimación o deslegitimación; en cuanto lugares de compra o venta donde también puede producirse la tertulia cotidiana, por ejemplo, o donde se disponen espacios de ocio y diversión, pues por "humilde" y precario que sea el barrio contará con ellos, a veces de ámbito y control municipal, pero en ocasiones simplemente legitimados por los usos del día a día.

La violencia social puede asimismo tener sus expresiones paisajísticas, tanto en la organización del espacio de los barrios, la división en zonas de control por parte de grupos pandilleros o maras, o la evidente presencia militar o policiaca, cuando el Estado se dota de una política ampliamente represiva. Por desgracia, esta violencia puede naturalizarse si persiste a lo largo de los años, de modo que se vuelve elemento integral de la cotidianidad.

${ }^{9}$ No quiero decir que la vida cotidiana se desarrolle aparte de la historia. Hay numerosos vasos comunicantes entre historia o contexto sociohistórico y vida cotidiana, pero para efectos analíticos en este texto se considera vida cotidiana ligada al hogar y al barrio como un ámbito específico de la existencia social, sin que eso signifique al margen de concatenaciones y determinaciones múltiples. 


\section{Paisajes y biografías}

El paisaje es a fin de cuentas biografía, es decir, historia personal. A lo largo de los apartados anteriores hemos postulado que el paisaje se hace social e históricamente. Sin desdecirnos, solo agregaremos que la historia social también se expresa en multiplicidad de biografías personales, que concretan la historia colectiva. No hay duda de que la historia social no es equivalente a la suma de las historias individuales, pero estas forman parte y se reflejan dialécticamente en la historia general.

El trabajo, las acciones colectivas y la vida cotidiana, como ya dijimos, construyen socialmente el paisaje. Es posible plantear que lo hacen a largo plazo. Como el paisaje se manifiesta geográficamente, los cambios en su apariencia a veces concurren en el transcurso de periodos muy prolongados. Puede suceder, claro está, que fenómenos de la naturaleza o del desarrollo social provoquen cambios bruscos del paisaje.

En consecuencia, pudiera ser que las historias individuales se inscriben en el marco de cambios paisajísticos relativamente imperceptibles, es decir, cuando en apariencia la historia se ha detenido en determinados lugares. Pero podría pensarse que esto no es lo común en el marco del capitalismo, pues ha sido el modo de producción que mayores y más rápidos cambios ha provocado y sigue provocando en el paisaje.

Por tanto, una a una las personas se inscriben al mismo tiempo en una historia paisajística como constructores individuales del paisaje, al menos en las dimensiones antes señaladas: trabajo, lucha social y vida cotidiana.

De ahí que sea posible esperar algunas correspondencias, no necesariamente mecánicas, entre historia social, y por ende historia del paisaje, con trayectorias de vida, esto es, con biografías específicas.

En términos metodológicos, esto nos lleva a vincular paisaje con historias de vida o, más en concreto, con relatos de vida. Podríamos denominar este enfoque como relatos temáticos de vida, pues el fragmento de experiencia vivida que más nos interesa en estos relatos es el de la relación entre individualidad y paisaje. ${ }^{10}$

${ }^{10}$ Debido a que las trayectorias de vida son tan variadas y multiformes, el relato de vida permite centrar las observaciones a partir de un tema, de una categoría o de un supuesto o concepto articulador (Bertaux, 2005: 18). 
Se trata de la relativa concurrencia entre historia social e individual. Al respecto vale destacar la perspectiva etnosociológica, que subraya las coincidencias entre las lógicas sociales y las individuales. Así:

La hipótesis central de la perspectiva etnosociológica es que las lógicas que rigen el conjunto del mundo social o mesocosmos se dan igualmente en cada uno de los microcosmos que lo componen: observando uno solo, o mejor varios de estos microcosmos, y por poco que se logre identificar las lógicas de acción, los mecanismos sociales, los procesos de reproducción y de transformación, se deberían captar al menos algunas de las lógicas sociales del mesocosmos mismo [Bertaux, 2005: 18].

Esperaremos que la reconstrucción individual del paisaje se exprese en una trayectoria de vida o, en las palabras de Bertaux, en un itinerario biográfico, al menos de las siguientes maneras:

\begin{tabular}{|c|c|c|c|}
\hline \multirow{2}{*}{ DIMENSIONES } & \multicolumn{3}{|c|}{ ITINERARIO BIOGRÁFICO } \\
\hline & INFANCIA Y JUVENTUD & $\begin{array}{l}\text { VIDA ADULTA } \\
\text { (VIDA COTIDIANA Y TRABAJO) }\end{array}$ & Vejez \\
\hline Trabajo & & $\begin{array}{l}\text { Reconstrucción física del } \\
\text { paisaje por medio del trabajo }\end{array}$ & \\
\hline Lucha social & & $\begin{array}{l}\text { Reconstrucción colectiva del } \\
\text { paisaje }\end{array}$ & \\
\hline Vida cotidiana & $\begin{array}{l}\text { Formación del "gusto } \\
\text { paisajístico" }\end{array}$ & $\begin{array}{l}\text { Reconstrucción del paisaje en } \\
\text { la vivienda y el barrio }\end{array}$ & $\begin{array}{l}\text { Nostalgia } \\
\text { del paisaje }\end{array}$ \\
\hline $\begin{array}{l}\text { Naturaleza (sin } \\
\text { cambios o con } \\
\text { cambios bruscos, } \\
\text { por ejemplo por } \\
\text { terremotos u } \\
\text { otros eventos) }\end{array}$ & \multicolumn{3}{|c|}{$\begin{array}{l}\text { Paisaje físico con escasos cambios o concurrencia de efectos } \\
\text { significativos }\end{array}$} \\
\hline
\end{tabular}

Fuente: Elaboración propia.

De acuerdo con lo anterior, en la infancia y en la juventud se formarían las coordenadas estéticas del paisaje. Sería una absorción inconsciente del disfrute del paisaje, a la que llamaremos formación del gusto paisajístico. En la vida 
adulta, tanto en lo laboral como en lo cotidiano, se expresaría sobre todo en la actuación real en el paisaje. Por lo que se refiere a la vejez, el énfasis sería nostálgico, aunque desde luego también continúan existiendo actuaciones reales sobre el paisaje e incluso se sigue formando el gusto paisajístico.

Por último, está la manifestación de la naturaleza como tal, que puede conllevar o no transformaciones bruscas, las cuales por lo general son registradas intensamente por la memoria individual.

Así, puede pensarse en registros paisajísticos a lo largo de un itinerario biográfico. El relato de vida, en cuanto testimonio de la experiencia concreta de vida, presenta de forma concatenada, esto es diacrónica, una sucesión de hechos a través del tiempo, que es también la dimensión de la articulación de factores y de mecanismos muy diversos, tanto en el orden del itinerario personal, como de las determinantes sociales que contextualizan y en cierta forma explican el devenir personal (Bertaux, 2005: 22).

\section{Dualidad sentimental del paisaje: como vivencia sufrida y como placer}

Desde un punto de vista muy subjetivo, el paisaje puede ser experimentado con dolor y rechazo (sufrimiento) o al contrario, como placer. Entre estos sentimientos extremos pueden existir diversas tonalidades y matices. Además, a lo largo del itinerario biográfico es posible hallar diferentes vivencias subjetivas del paisaje.

Desde una óptica radical podemos decir que en el capitalismo el paisaje es opresivo para las grandes mayorías que no tienen otra opción que vivir de la venta de su fuerza de trabajo; esto es el campo de la explotación. ${ }^{11}$ El paisaje se les presentará del todo ajeno, pues literalmente no les pertenece, ya que es erigido desde el interés económico dominante. En el ámbito urbano, se trata del espacio de las fábricas y de los establecimientos financieros y comerciales que en esencia es propiedad privada. En el contexto rural, el paisaje ajeno se levanta a partir de las grandes explotaciones agrocapitalistas, piénsese en el café, la

${ }^{11}$ La teorización del campo de explotación como disputa de excedentes y relacionado con la exclusión social puede consultarse en Pérez Sáinz (2012). Para abundar sobre la aplicación de esta teoría a los movimientos sociales consúltese Cordero Ulate (2009). 
Paisajes y relatos de vida. Apuntes para la interpretación de los paisajes socioculturales.

caña de azúcar, el cacao, entre otros. Con base en la conceptualización de la Unesco, estos paisajes pueden considerarse paisajes culturales.

Hay zonas intermedias en la estructura económica, como la pequeña propiedad. En la conformación urbana pueden ser los pequeños comercios, pulperías y tiendas; mientras que en las zonas turísticas serían los pequeños negocios de propiedad individual dirigidos a brindar servicios a los turistas. Por su parte, en las zonas rurales, podría darse el caso de que algunas áreas de la economía, por ejemplo el cultivo de café, esté en manos de pequeños o medianos propietarios locales.

La pequeña propiedad urbana o rural es económicamente contradictoria, pues por lo común se encuentra en posiciones de subordinación respecto a la gran producción capitalista, pero por otro lado cuenta con parte de los recursos productivos, ya sean los establecimientos y las máquinas o la tierra, de ahí que, en cierto modo, el paisaje le pertenece, aunque de manera precaria o subordinada.

Otra zona "intermedia" del trabajo es la que ocurre en el propio Estado. Si bien se está hablando de un Estado capitalista, el trabajo en él a veces manifiesta importantes (y al mismo tiempo relativos) avances, por ejemplo en salud o educación. De forma que, el trabajo en determinados espacios estatales puede percibirse como "sustraído a la acumulación” y, más bien, dedicado a una construcción social progresista y liberadora de la sociedad. Además, es en el Estado donde se tiene un empleo mejor pagado y con mejores condiciones laborales, en gran medida por las luchas sindicales y sociales que se han emprendido en su seno. En Costa Rica esto sigue siendo así; por ejemplo, en términos generales, el empleo que se produce en turismo sigue siendo de inferior calidad que aquel que ofrecen las instituciones del Estado.

En consecuencia, sería dable considerar que el paisaje construido en el trabajo generaría dolor y por ende rechazo y a veces malos recuerdos. No obstante ¿por qué en ocasiones el paisaje se siente con placer?

Una posible respuesta es el contrapunto del trabajo, que sería el ocio. Como se sabe, el lugar del ocio es principalmente la vida cotidiana. Tal como se dijo, esta sería la existencia individual que se expresa en el campo del hogar ( $\sin$ importar su tamaño y características) y en el barrio, vinculado con el disfrute del tiempo libre en lo que más gusta: la tertulia, los amigos y una diversidad de actividades lúdicas. La vida cotidiana placentera se desarrolla en el día a día, así sea mediante pequeños espacios "sustraídos" al trabajo, pero adquiere su máximo despliegue en las vacaciones o durante los fines de semana. 
La calidad del trabajo está mediada justamente por la relación entre horas de trabajo y horas "libres". Un trabajo de mayor calidad será el mejor pagado por horas; por ende, en principio, con mayor cantidad de horas libres. De ahí que sea aceptable postular que la construcción placentera del paisaje acontece de manera señalada en la vida cotidiana dedicada al ocio. Puede indicarse además que, si bien el trabajo es el lugar del paisaje doloroso, esto se compensa en alguna medida cuando se piensa en los espacios de ocio o descanso que también hay en el propio trabajo, asociados por lo regular a las horas de comida y los amigos(as) que allí puede haber, o con los espacios más estructurados, como la variedad de actividades sociales y recreativas que, dependiendo del empleo, se organizan.

\section{Turismo y paisaje}

El turismo tiene lugar en sociedades concretas. No se da en un mundo aparte de la geografía, del modo de producción ni de las luchas sociales que ocurren en determinados contextos. Por más que, desde ciertas estéticas turísticas, se quiera independizar al turista de las historias locales, esto es imposible, pues el contexto social real se filtrará en la experiencia turística.

En el turismo, los paisajes locales se recrean a través de manifestaciones como las siguientes:

- Revalorizando algunos paisajes donde el trabajo fue constitutivo de ellos. En Puntarenas centro, el eje articulador del trabajo era el muelle donde atracaban los barcos mercantes y de pasajeros. El muelle histórico de Puntarenas (que como se sabe se ha trasladado a Caldera) era un hormiguero humano de trabajo, por las centenas de trabajadores cargando y descargando barcos. Este paisaje de trabajo era muy gustado por los turistas costarricenses de los años sesenta y setenta, que viajaban a Puntarenas en sus cortas vacaciones.

- Desvalorizando otros paisajes en función de la "evolución” de los gustos turísticos y las tendencias del mercado. Volviendo al ejemplo de Puntarenas, el paisaje del estero (que también fue muy gustado por los turistas, sobre todo visto desde el mercado) se ha ido desvalorizando, tal vez en razón de la contaminación fecal, el crecimiento poblacional y los asentamientos 
precarios a su alrededor. No obstante, es probable que el paisaje del estero siga siendo apreciado por los habitantes locales de los nuevos asentamientos precarios, algunos de estos últimos en proceso de consolidación y mejoramiento.

- Creando nuevos paisajes donde el ocio y la recreación son sus fuerzas constituyentes. De igual modo son importantes los paisajes del ocio, construidos por los pobladores locales. El turismo tiende a reutilizar y, por consecuencia, a resignificar los espacios originarios del ocio. El llamado paseo de los turistas en Puntarenas es quizá el máximo paisaje del placer puntarenense, a partir del cual pueden disfrutarse su larga playa, sus atardeceres rojizos, las cervezas y el baile en sus bares y salones. Nuestra pequeña "Copacabana”. La construcción social de este paisaje mezcla al habitante local, que lo ha vivido y usado, con el turista que ha ratificado y recreado este gusto.

\section{Los paisajes de Puntarenas y Limón centro}

En Puntarenas y Limón, los principales puertos de Costa Rica, destacan como articuladores de los paisajes socioculturales:

- El transporte ferroviario y acuático, incluyendo sus puertos

- Los mercados, en concreto los mercados centrales

- Los paisajes étnicos

- Los paisajes de ocio y recreación ${ }^{12}$

Tanto en Puntarenas como en Limón, la actividad portuaria representa el eje principal de la economía local. Asimismo, estos puertos son esenciales para la relación internacional de la economía costarricense. Por muchos años, el empleo generado por la actividad portuaria fue público. Esto ya no es así en Puntarenas, mientras que en Limón es objeto de una crisis sociopolítica tal vez solo comparable con la salida de la Compañía Bananera. De manera que el tema central para el futuro de estos lugares es cómo encontrar nuevos espacios

${ }^{12}$ Los proyectos de investigación sobre turismo que se han desarrollado desde la Escuela de Sociología de la Universidad de Costa Rica y de las sedes de El Pacífico y de Limón han aportado al conocimiento de la historia y del impacto del turismo en Puntarenas y Limón centro. Véase al respecto Cordero Ulate (2010, 2011a y 2011b) y Chen Mok y García Cousin (2007 y 2010). 
de empleo y, por ende, cierta realización social, si se me permite hablar en estos términos. En tal marco, el tema del modelo de turismo posible y deseable es de mucha trascendencia. Las posibles alternativas de empleo, incluyendo el modelo turístico deseable, son independientes de la resolución que al final tenga la crisis del empleo público. Desde luego, tal problemática no es solo esencial desde un punto de vista académico, sino que es vital para significativos sectores sociales de estos lugares.

En el caso de Limón centro, el puerto y el ferrocarril (con una parte significativa de su población negra y china combinada con la población mestiza) crearon un paisaje asentado en un espacio geográfico de mar azul, con barcos anclados y una pequeña isla al fondo. Un paisaje urbano con algunas construcciones emblemáticas de arquitectura (victoriano caribeño, entre otras) conectado con el valle central por el tren que atravesaba sus densas montañas y que avanzaba la mayor parte de su recorrido al lado del río Reventazón, con sus pueblos negros y sus comidas diferenciadas, con su inglés. La construcción social de este paisaje estaba dada en primera instancia por el modo de producción, es decir, por la economía exportadora, por la república exportadora que empezaba a ganar fama por no tener dictadura militar, por distribuir de mejor manera el producto social, aunque a la vez fuera portadora de la desigualdad social que se observaba desde el tren, porque lo que se miraba a través de la ventana del ferrocarril y en el puerto era a la gente trabajadora, no a los dueños de las plantaciones, que estaban en otro país.

Persisten el mar azul limonense, con su isla Uvita al fondo y las olas blancas que rompen en el tajamar. La población negra, china y mestiza sigue trabajando y viviendo ese paisaje. El modo de producción continúa siendo el mismo, pero se le han introducido cambios puntuales que van alterando el paisaje. Un paisaje que es creado por sus artistas, pero sobre todo por su gente de trabajo y que, de igual forma, es creado y alterado por los turistas. Un paisaje que se sufre y se ama inmensamente. 
Paisajes y relatos de vida. Apuntes para la interpretación de los paisajes socioculturales.

\section{Fuentes CONSULtadas}

Bertaux, Daniel (2005). Los relatos de vida. Perspectiva etnosociológica. Barcelona: Edicions Bellaterra. [(1997). Les récits de vie. Nathan-Université.]

Castells, Manuel (1974). Movimientos sociales urbanos. Madrid: Siglo XXI.

Chen Mok, Susan y Kathia García Cousin (2007). "Puntarenas y el turismo: ¿Qué ha pasado con la 'Perla del Pacífico'?” InterSedes, Revista de las Sedes Regionales, VIII (15), 109-131.

(2010). "Percepción del impacto del turismo en El Roble 2 de Puntarenas, Costa Rica”. Reflexiones, 89 (2), 27-38.

Cordero Ulate, Allen (2009). "Nuevas desigualdades; nuevas resistencias. El caso de los ex-trabajadores bananeros costarricenses afectados por los agroquímicos”. Revista Centroamericana de Ciencias Sociales, VI (2), 75-100.

----- (2010). “Allá en las Playas del Coco donde el turismo no fue amor de temporada”. InterSedes, Revista de las Sedes Regionales, XI (22), 154-179. (2011a). "La vertiente social de los centros históricos del turismo: Los casos de Playas del Coco, Limón y Puntarenas”, en Ernest Cañada Mullor y Macià Blázquez (eds.). Turismo placebo. Nueva colonización turística: Del Mediterráneo a Mesoamérica y el Caribe. Lógicas espaciales del capital turístico. Managua: Edisa, 135-162.

(2011b). "Los viejos y olvidados centros históricos del turismo: algunas evidencias para el caso costarricense", en Allen Cordero Ulate y Paul Bodson (eds.). ¿Es posible otro turismo? Su realidad centroamericana, nueve casos de estudio, vol. II. San José, Costa Rica: Facultad Latinoamericana de Ciencias Sociales (Flacso), 1-17.

----- (en prensa). "Paisajes de paisajes. Comprensión del paisaje desde la ecología política”.

Heller, Agnes (1972). Historia y vida cotidiana: aportación a la sociología socialista. México: Grijalbo.

Mandel, Ernest (1974). Traité d'économie marxiste. París: Editions 10/18.

Marx, Karl (1948). Le Capital. Critique de l'economie politique. París: Editions Sociales.

(1972). Contribution à la critique de l'économie politique. París: Editions Sociales. 
Mitchell, Don (2007). "Muerte entre la abundancia: los paisajes como sistemas de reproducción social”, en Joan Nogué (ed.). La construcción social del paisaje. Madrid: Biblioteca Nueva, 85-106.

Nogué, Joan (ed.) (2007). La construcción social del paisaje. Madrid: Biblioteca Nueva.

Oslender, Ulrich (2002). "Espacio, lugar y movimientos sociales: hacia una 'espacialidad de resistencia'”. Scripta Nova. Revista Electrónica de Geografía y Ciencias Sociales [en línea], VI (115). Disponible en: http://www. ub.es/geocrit/sn/sn-115.htm

Pérez Sáinz, Juan Pablo (2012). Sociedades fracturadas. La exclusión social en Centroamérica. San José, Costa Rica: Flacso.

Roger, Alain (1997). Court traité du paysage. París: Gallimard. ----- (2007). Breve tratado del paisaje. Madrid: Biblioteca Nueva.

Sartre, Jean Paul (1960). Critique de la raison dialectique. París: Gallimard.

----- (1964). Lo imaginario. Buenos Aires: Losada. [(1940). L' imaginaire.

Psychologie phénoménologique de l' imagination. París: Gallimard.]

Unesco (2002). Paisajes culturales en Mesoamérica: Memoria. Reunión de Expertos sobre los Paisajes Culturales en Mesoamérica. San José de Costa Rica: Oficina de la Unesco para América Central.

Watsuji, Tetsuro (2006). Antropología del paisaje, climas y culturas y religiones. Salamanca: Ediciones Sígueme. 